\title{
BMJ Open Consultants as victims of bullying and undermining: a survey of Royal College of Obstetricians and Gynaecologists consultant experiences
}

\author{
Tariq Shabazz, ${ }^{1}$ William Parry-Smith, ${ }^{1}$ Sharon Oates, ${ }^{2}$ Steven Henderson, ${ }^{3}$ \\ Joanna Mountfield ${ }^{1}$
}

To cite: Shabazz T, ParrySmith W, Oates S, et al. Consultants as victims of bullying and undermining: a survey of Royal College of Obstetricians and Gynaecologists consultant experiences. BMJ Open 2016;6: 011462.

doi:10.1136/bmjopen-2016011462

- Prepublication history and additional material is available. To view please visit the journal (http://dx.doi.org/ 10.1136/bmjopen-2016011462).

Received 16 February 2016 Revised 22 April 2016 Accepted 26 May 2016

CrossMark

\begin{abstract}
${ }^{1}$ Royal College of
Obstetricians and

Gynaecologists, London, UK

${ }^{2}$ RCOG Workplace Behaviour Champion, Shrewsbury and

Telford Hospitals Trust,

Princess Royal Hospital,

Telford, UK

${ }^{3} \mathrm{Head}$ of Impact and Social Innovation, Southampton

Solent University,
\end{abstract}

Southampton, Hampshire, UK

Correspondence to

Professor Steven Henderson; steven.henderson@solent. ac.uk

\section{ABSTRACT}

Objective: To explore incidents of bullying and undermining among obstetrics and gynaecology $(0 \& G)$ consultants in the UK, to add another dimension to previous research and assist in providing a more holistic understanding of the problem in medicine.

Design: Questionnaire survey.

Setting: Royal College of Obstetricians and Gynaecologists (RCOG).

Participants: $0 \& G$ consultant members/fellows of the RCOG working in the UK.

Main outcome measures: Measures included a typology of 4 bullying and undermining consequences from major to coping.

Results: There was a 28\% (664) response rate of whom $44 \%$ (229) responded that they had been persistently bullied or undermined. Victims responded that bullying and undermining is carried out by those senior or at least close in the hierarchy. Of the 278 consultants who answered the question on 'frequency of occurrence', $50 \%$ stated that bullying and undermining occurs on half, or more, of all encounters with perpetrators and two-thirds reported that it had lasted more than 3 years. The reported impact on professional and personal life spans a wide spectrum from suicidal ideation, depression and sleep disturbance, and a loss of confidence. Over half reported problems that could compromise patient care. When victims were asked if the problem was being addressed, $73 \%$ of those that responded stated that it was not.

Conclusions: Significant numbers of consultants in $0 \& G$ in the UK are victims of bullying and undermining behaviour that puts their own health and patient care at risk. New interventions to tackle the problem, rather than its consequences, are required urgently, together with greater commitment to supporting such interventions.

\section{INTRODUCTION}

Research on bullying and undermining in medicine concludes that the problem is widespread and pernicious in nature and under-

\section{Strengths and limitations of this study}

- The study is the first college-level investigation into bullying and undermining at level of senior physicians. It reveals a hitherto unknown incidence of consultants as victims rather than perpetrators, and the scale of the suffering that seniors cause each other.

- The large number of variables implicated: male/ female, UK/overseas trained, location, perpetrator, etc, made detailed statistical analysis problematic. Hence, there are no speculations on what might be the general case.

- It is probable that victims are over-represented in the sample. Hence, the study does not infer relationships applying to the wider population.

reported in National Health Service (NHS) units and embedded as an experience from the earliest days of a trainee's career. ${ }^{1-6}$ The impact on a victim's personal and professional life may range from a loss of confidence/depression, which subsequently impacts on a doctor's competence and the level of patient care provided, to destruction of health and family life, serious psychological damage and suicidal ideation. It can distract clinicians' attention from vital information which could in turn lead to serious or fatal errors, not only confined to operating theatres. ${ }^{6-13}$ Consequences for organisations include absences from work, low job satisfaction, high staff turnover, unnecessary additional financial costs. ${ }^{8-15}$

Individuals who raise concerns about problems in their organisation are often treated negatively and subjected to processes described as 'harrowing and isolating'. 7 Instances where individuals who raised concerns were treated positively, were found to be within organisations that promote '...a culture of openness, [had] a good knowledge of whistleblowing policies and procedures, 
[provided support for whistle blowers] during the process, and [maintained] good working relationships with colleagues'. ${ }^{7}$ Management and leadership styles are known to influence bullying and undermining in the workplace and play a central role in increasing or decreasing such behaviour. ${ }^{13}$ Yet the continued omnipresence of bullying and undermining in the health sector suggests that these best practices are not universal.

A number of interventions to control or stop bullying and undermining behaviour have been described in the literature, ${ }^{14-18}$ although as Illing et $a l^{13}$ point out trenchantly, few such interventions have been evaluated adequately in healthcare. Some interventions focus on the resilience of the victim, offering 'cognitive rehearsal of responses to common bullying behaviour'. ${ }^{15}$ Assertiveness and aggression training programmes have been used to assist individuals to deal with difficult situations in the workplace. ${ }^{16}$ Others include social and behavioural skills group training, inclusion of interpersonal skills in the training curriculum, and mentoring. ${ }^{17}$ Institutional interventions enhance reporting mechanisms to facilitate reporting of bullying ${ }^{18}$ and greater support for whistle blowers. ${ }^{15}$ Such interventions are often supported by 'Informational or media campaigns to change policy [and] incentives to change/adhere to policies'. ${ }^{14} 18$ Two things are evident however. First the majority of these interventions focus on the victim, or the organisation, rather than the perpetrator. Second, it is assumed, or inferred from the literature, that the victim needs such support because they have less standing in the organisation than the perpetrator. Thus, while studies of bullying and undermining of nurses by nurse managers and clinicians, and of trainee doctors bullied by consultants and managers are common, consultants themselves are seldom considered as victims. This paper seeks to fill this important gap in our understanding of bullying and undermining in the health sector.

\section{The consultant as victim}

A UK medical consultant is a senior medical practitioner who has completed their training and is registered on the General Medical Council Specialty Register (usually requiring more than 8 years postgraduate experience in their specialty). They would have been appointed to their NHS consultant post in open competition. Consultant medical staff are often identified in studies as the main source of bullying and undermining, particularly towards trainees, but no published comprehensive study has examined UK consultants as victims. Consequently, the full extent of the problem and the impact on the personal and professional life of consultants is not known. This research aimed to reveal the extent, nature and consequences of bullying and undermining of obstetrics and gynaecology (O\&G) consultants to enable a more holistic understanding.

\section{Methodology}

The research framework was created from a review of the literature, particularly the NHS Staff Survey ${ }^{19}{ }^{20}$ and Unison, ${ }^{21}$ the Royal College of Obstetricians and Gynaecologists (RCOG) Trainee Evaluation Form feedback (personal communication), and a cross-sectional survey of the undergraduates, trainees and consultants in O\&G in the West Midlands. ${ }^{22}$ Structured interviews, based on these finding, were carried out with RCOG consultants to develop and refine questions (see online supplementary appendix).

Consequently, most of the questions were closed answer questions-such as those asking those reporting that they had been bullied or undermined to indicate the status of perpetrator, types of offensive behaviour and age range. Other questions requested straightforward data such as region or job title. The exception concerned the part of the survey examining the effects of bullying and undermining behaviours that included freetext boxes. Participants used free-text boxes to comment on their experiences of bullying and undermining, and were asked how such behaviour impacted on their professional and personal life. The 236 comments considered were put into four categories, namely major, moderate, minor and coping. The comments were categorised by using key words mentioned in the survey responses. These are as follows:

1. Major-suicide, illness, sick leave, early retirement, moving or moved posts, depression requiring medication or therapy.

2. Moderate-struggle to work, fear, resigned from positions in the Trust, considering moving, stress requiring help, significant sleep disturbance requiring medical attention, relationship and home life problems, reduced confidence.

3. Minor-demoralised, sleep loss that has not been treated, isolation, stress but not affecting patient care, feel resigned, putting up, come to work to pay bills.

4. Coping - stand up to it, avoid certain individuals, getting on, head down, no effect.

Individual consultants reporting bullying and undermining behaviours were classified according to their most significant impact.

Those that had tried to seek resolution through formal processes were also given the opportunity to write of their experiences in free-text boxes. A selection of the quotes has been chosen to illustrate the general dissatisfaction with process and outcome implied by the survey data.

The RCOG reviewed the survey before it went live and deemed that further ethical approval was not required. In addition to some personal details (although the survey was anonymous), respondents were asked about their experiences as a victim (if any), the nature and duration of bullying and undermining behaviours and the standing of the perpetrator. The effects on personal and professional life were explored, together with the experiences of using formal reporting and disciplinary processes. 
The sampling frame was the roll of 2404 consultants within the UK generated by the RCOG membership department. Consultants were contacted via email and provided with a short summary of the research project and Rayner and Hoel's ${ }^{23}$ taxonomy of bullying and undermining behaviours to ensure commonality. The email also contained assurances of anonymity and a web link to the survey that remained live for 3 weeks.

\section{RESULTS}

There was a $28 \%$ (664) response rate. Of those that responded, $47 \%$ (314) were male and $53 \%$ (350) female, over half were age 45-54 years $(52 \%)$, followed by 55-64 (22\%), 35-44 (22\%) and 65-74 (3\%). All deaneries/Local Education and Training Boards (LETBs) were represented by at least 20 respondents. Those completing their postgraduate training in the UK accounted for $98 \%$ of respondents and $78 \%$ were working full time. Some fifth (22\%) of respondents were in Trust management roles (small numbers of respondents did not give details of location or age-these have been omitted from the summary here).

Since the questionnaire concerned bullying and undermining behaviour, it is likely that victims are overrepresented as a proportion of the sample since they may be more motivated to complete the online questionnaire. That said, some 290 consultants (44\% of sample) responded that they had been persistently bullied or undermined. Between $19 \%$ and $45 \%$ of all respondents believed there to be a general bullying and undermining problem in their unit, depending on their location as defined by deanery/LETB. Non-UK males and females figured prominently in the sample of those reporting bullying and undermining behaviours, even though they were a relatively small proportion of the overall response. More UK qualified females report such behaviours than male UK qualified consultants. ${ }^{\mathrm{i}}$

These 290 that reported themselves victims of bullying and undermining behaviour constitute more than $14 \%$ of the total RCOG consultant body working in the UK. This figure is not dissimilar from that reported by Illing for levels of bullying elsewhere if one assumes that all victims have completed the survey. That is to say that even if response bias is accepted and the sample overrepresents the proportion of victims in the wider population, the data presented below nonetheless capture the

\footnotetext{
${ }^{\mathrm{i}}$ The strong assumption is that the sample proportions are close to the population proportions. Using a two-sample $\mathrm{z}$ test to compare sample proportions, the null hypothesis that men and women consultants are equally likely to report themselves as victims of bullying is rejected at $\mathrm{p}<0.001$, as are the null hypotheses that UK trained consultants are equally likely to report themselves as victims as those trained abroad and UK trained women report these behaviours equally with non-UK trained women. The null hypothesis is accepted at $\mathrm{p}<0.05$ when comparing the sample of consultants who have management positions with those who do not, and UK trained males with those trained abroad. That said the authors find no reasons, compelling or slight, to accept the strong assumption.
}

experience of a segment of the RCOG membership usually thought of as perpetrators rather than victims. The data do not claim to be representative of a wider population of victims since the sample is self-selecting. Indeed, the diversity of experience reported here undermines the notion of a central tendency of victimhood.

\section{Types of bullying and undermining behaviours}

The types of behaviours most reported were persistent attempts to belittle and undermine an individual's work; undermining an individual's integrity; persistent and unjustified criticism and monitoring of work; freezing out, ignoring or excluding and continual undervaluing of an individual's effort. The sharing of emails (copied in or blind copied in), containing criticism or alluding to poor performance that should have been dealt with person to person seemed to be a subtle and effective strategy used by perpetrators to bully and undermine. Physical and sexual abuse was reported by only a very small number of consultants $(0.4 \%$ and $1.8 \%$, respectively).

\section{Who are the perpetrators?}

The survey sought to uncover whether perpetrators were individuals acting maliciously but alone, or whether they were bullying as a coordinated group. Some 2/3 of respondents indicated that the bullying and undermining was perpetrated by one or more individuals acting independently (112 reporting a sole bully, 92 citing more than one individual). When asked for the role of perpetrators, unprompted responses included lead clinicians, clinical directors, clinical secretaries, career grade doctors, patients, administration managers, general practitioners and board-level executives. The remaining $1 / 3$ (86 respondents) who reported individuals acting maliciously together identified managers, senior consultants and medical directors as culprits. Victims report that most bullying and undermining is carried out by those senior or at least close in the hierarchy. Such colleagues as nurses, midwives, consultants from other specialties and managers are more likely to be involved where there are multiple sources of bullying than the sole perpetrator. Bullying from juniors, often called upward bullying, accounts for some $12 \%$ of those claiming to be victims of bullying and undermining (generally consistent with concerns reported by participants around feedback and training of challenging trainees).

Both males and females were reported as perpetrators, with $37 \%$ reporting predominantly males, $28 \%$ reporting predominately females, with the remainder citing both equally. It is clear that although this paper focuses on the consultant as victim, the key perpetrators are other consultants and many junior consultants have already learned these behaviours (see table 1).

\section{Duration and frequency}

Alarmingly, two-thirds of victims report that the behaviour had been occurring for longer than 3 years (see table 2). 
Table 1 Individual perpetrators of bullying and undermining behaviour

\section{Perpetrator}

Frequency

Senior consultant 57

Junior consultant 25

Manager

Medical director

2

Others

5

Undeclared

20

Total

112

Table 2 Duration of bullying and undermining experience Duration Percentage

Over the last 12 months 9.3

Over the last couple of years

26.1

Over the last $3-5$ years

Longer than 5 years

Not only are these behaviours longstanding, but they are also frequent. Of the 278 consultants who answered the question, $50 \%$ stated that bullying and undermining occurs on half, or more, of all encounters with perpetrators, with $13 \%$ reporting that all encounters lead to such behaviours. The impact on consultants' professional and personal lives is illustrated (see table 3).

As table 3 shows, two-third of consultants identifying themselves as victims of bullying and undermining suffer major or moderate effects as defined in the methodology section above. The significance for patient safety is clear. At least $8 \%$ of consultants registered with the RCOG have indicated that bullying and undermining behaviour causes them such problems as significant sleep loss, reduced confidence, depression and illness, for example. This alone should raise anxieties for patient safety and add to similar conclusions drawn by Francis $^{7}$ and Illing ${ }^{13}$ among others.

\section{Management of bullying and undermining/outcome of reported cases}

When asked if the problem was being addressed, $73 \%$ of those who answered this question stated that it was not. Only 140 had reported the behaviour to the relevant individuals in their Trusts. Of these, 110 indicated the consequence; as shown in table 4 below. Out of the $57 \%$

Table 3 Effects of bullying and undermining on consultants

\begin{tabular}{ll}
\hline Impact on professional and personal life & \\
\hline Category & Percentage \\
\hline Major & 22 \\
Moderate & 44 \\
Minor & 27 \\
Coping & 7 \\
\hline
\end{tabular}

Table 4 Outcome of reporting bullying and undermining behaviour

\begin{tabular}{lc}
\hline Outcome & Percentage \\
\hline Issue resolved and behaviour stopped & 4 \\
Issues resolved but behaviour recurred & 7 \\
Issue addressed but not resolved and & 32 \\
behaviour continued & 57 \\
Issue not resolved & \\
\hline
\end{tabular}

who reported that the issues had not been addressed, $48 \%$ reported that the behaviour continued, while 9\% reported that the behaviour had stopped (eg, after the perpetrator(s) had moved on to another role). In one typical example, the victim was told "this is how the [perpetrator] speaks" and no further action was taken. Rather than address the way the perpetrator 'speaks' through some intervention, the onus was placed on the victim to accept behaviour that should be considered unacceptable. Only $4 \%$ of cases were resolved. A selection of direct quotes from those believing that they had been let down by the formal reporting and disciplinary procedures are illustrated (see box 1 ).

\section{CONCLUSION}

A substantial proportion of the consultant members of RCOG working in the UK indicate that they have experienced bullying and undermining behaviour. In many cases, the behaviour has persisted for years. In addition to their own distress, patient safety is compromised by the effects identified in the taxonomy. Those that report such behaviours are rarely satisfied that the issues have been addressed.

The situation is clearly unacceptable from every point of view. Such recent initiatives as the Royal College of Obstetricians and Gynecologists and Royal College of Midwives joint statement regarding zero tolerance ${ }^{\mathrm{ii}} 4$ and new RCOG initiatives such as the bullying and undermining toolkit, eLearning module, and the establishment of National Workplace Behaviours Advisory Network \& Workplace Behaviours Champions are to be welcomed. $^{24}$

Yet this research shows emphatically that the immediate situation is disturbing and unacceptable. Without wishing to diminish the importance of steps already taken, much more needs to be done by institutions on designing interventions that tackle bullying and undermining behaviours directly rather that those that seek to minimise consequences. Such interventions need to be both local, through healthcare providers, and national through colleges. Such interventions must include an overhaul of the current inadequate reporting and

\footnotetext{
${ }^{i i}$ https://www.rcog.org.uk/globalassets/documents/careers-andtraining/workplace-and-workforce-issues/rcog-rcm-statementundermining-behaviours-oct-15.pdf
} 
Box 1 Quotes from consultants using formal processes of redress

1. I reported only the tip of the iceberg. Unfortunately in those few situations the matter remained unabated.

2. Initially on two occasions the behaviour was stopped but eventually persisted and resulted in me having to leave the post.

3. The issue was not addressed and the issue with management and the senior consultant was brushed under the carpet.

4. The chief investigator was the friend of the medical director and the investigation was a white-wash.

5. The supposed investigation was an absolute disgrace, with the perpetrator eventually getting senior management roles.

6. Attempts made to facilitate change. This was just a tick box exercise. Behaviour continues and situation stays unresolved.

7. It was half-heartedly addressed and is either resolved or is further under the radar at present.

8. Investigation process is not very fair and is very stressful.

9. Action will not be taken against certain individuals because of who they are.

investigation processes that not only leaves those who complain stressed by the process and unsatisfied at the outcome, but also deters others from complaining. What is more, both preventive and disciplinary interventions require effective evaluation and thought should be given to effective monitoring of the feedback through both established mechanisms such as the NHS Staff Survey but also more widely, potentially through the collaboration of colleges. The RCOG has developed an action plan for ongoing work to help tackle bullying and undermining behaviour at all levels. Finally, we would call for regulators such as the Care Quality Commission, via its leadership domain, to consider this agenda more explicitly given the impact on staff and patients.

Acknowledgements The authors would like to thank the following for their support: Dr Clare McKenzie FRCOG for formal approval and support, Ms Kim Scrivener for sponsoring the research, Mr Angelo Lovino for assisting with the survey design, Mr Andrew Watson FRCOG for the peer review, Dr Felicity Ashworth FRCOG for the peer review and Professor David Watkins for critical review.

Contributors TS conceived the research topic and designed the study, and was supported by JM, WP-S and SO. The data were collected and analysed by TS, SO and WP-S under the supervision of JM. The manuscript was drafted by TS, SH and JM. The manuscript was critically revised for important intellectual content, and all authors contributed. TS and JM are the guarantors. TS was involved in original design of methodology and method, application of research method; extensive literature review; collation, presentation and analysis of data production of complete first draft. WP-S was involved in design of research method, analysis of data; critical review all drafts; drafting of significant amendments. SO was involved in design of research method, analysis of data. JM is project lead; and was involved in design of methodology, interpretation of data. SH was involved in second analysis and reinterpretation of data; extensive editing and review of first and subsequent drafts.

Funding TS was employed by Royal College of Obstetricians and Gynaecologists (RCOG) to carry out this research and other projects. The researchers created and had access to the entire data set. The final draft was formally approved for publication without change by RCOG officers.
Competing interests All authors have completed the ICMJE uniform disclosure form at http://www.icmje.org/coi_disclosure.pdf and declare two potential conflicting interests: TS was employed by the RCOG and received some financial support for the submitted work. JM is the unpaid RCOG Workplace Behaviours Advisor and is reimbursed for travel and accommodation expenses where appropriate when on RCOG business.

Ethics approval The RCOG reviewed the survey before it went live and deemed that further ethical approval was not required. The survey was signed off by Dr Clare McKenzie FRCOG-Vice President of Education.

Provenance and peer review Not commissioned; externally peer reviewed.

Data sharing statement Additional data from the survey of RCOG consultants are available from JM at Joanna.mountfield@uhs.nhs.uk.

Open Access This is an Open Access article distributed in accordance with the Creative Commons Attribution Non Commercial (CC BY-NC 4.0) license, which permits others to distribute, remix, adapt, build upon this work noncommercially, and license their derivative works on different terms, provided the original work is properly cited and the use is non-commercial. See: http:// creativecommons.org/licenses/by-nc/4.0/

\section{REFERENCES}

1. Carter $\mathrm{M}$, Thompson $\mathrm{N}$, Crampton $\mathrm{P}$, et al. Workplace bullying in the UK NHS: a questionnaire and interview study on prevalence, impact and barriers to reporting. BMJ Open 2013;3:e002628.

2. General Medical Council. National Training Survey 2014: key findings. June 2014. http://www.gmcuk.org/National_training_survey_2014 key_findings_report_1114.pdf_58504492.pdf (accessed 14 Nov 2014).

3. General Medical Council. National Training Survey 2013: key findings. June 2013. http://www.gmcuk.org/National_training_survey_key_ findings_report_2013.pdf_52299037.pdf (accessed 14 Nov 2014).

4. Timm A. 'It would not be tolerated in any other profession except medicine': survey reporting on undergraduates' exposure to bullying and harassment in their first placement year. BMJ Open 2014;4:e005140.

5. Wild JR, Ferguson HJ, McDermott FD, et al. Undermining and bullying in surgical training: a review and recommendations by the Association of Surgeons in Training. Int J Surg 2015;23(Suppl 1):S5-9.

6. Medical and Dental Defence Union of Scotland. Undermining patient safety. March 2014. http://www.mddus.com/resources/resource-type/ publications/gpst/gpst-issue-08/undermining-patient-safety/ (accessed 12 Jan 2015).

7. Francis R. Freedom to Speak Up Review Report. February 2015. https://freedomtospeakup.org.uk/the-report/ (accessed: 15 Feb 2015).

8. Francis R. Report of the Mid Staffordshire NHS Foundation Trust Public Inquiry. February 2013. http://www.midstaffspublicinquiry.com/ report (accessed 25 Nov 2014).

9. Quine L. Workplace bullying, psychological distress and job satisfaction in junior doctors. Camb Q Healthc Ethics 2003;12:91-101.

10. Quine L. Workplace bullying in NHS community trust: staff questionnaire survey. BMJ 1999;318:228-32.

11. Askew DA, Schluter PJ, Dick ML, et al. Bullying in the Australian medical workforce: cross-sectional data from an Australian e-Cohort study. Aust Health Rev 2012;36:197-204.

12. Hoosen IA, Callaghan R. A survey of workplace bullying of psychiatric trainees in the West Midlands. Psychiatr Bull 2004;28:225-7.

13. Illing CJ, Carter M, Thompson JN, et al. Evidence synthesis on the occurrence, causes, consequences, prevention and management of bullying and harassing behaviours to inform decision making in the NHS. http://dro.dur.ac.uk/10533/1/10533.pdf?DDD45+DDC42 +Clfc44 (20 Nov 2014).

14. Felblinger MD. Bullying, incivility, and disruptive behaviors in the healthcare setting: identification, impact and intervention. Front Health Serv Manag 2007;25:13-20.

15. Stagg SJ, Sheridan D. Effectiveness of bullying and violence prevention programs. AAOHN J 2010;58:419-24.

16. Oostrom JK, van Mierlo $\mathrm{H}$. An evaluation of an aggression management training program to cope with workplace violence in the healthcare sector. Res Nurs Health 2008;31:320-8.

17. Vreeman RC, Carroll AE. A systematic review of school-based interventions to prevent bullying. Arch Pediatr Adolesc Med 2007:161:78-88.

18. Gillen AP, Sinclair M, Kernoham GW, et al. Interventions for prevention of bullying in the workplace. Cochrane Database Syst Rev 2012;4:1-7. 
19. National Health Service. Focussed on staff experience. 2013. http:// www.nhsstaffsurveys.com/page/1006/Latest-Results/2013-Results/ (accessed 20 Sep 2014).

20. NHS National Services Scotland. NHS Scotland Staff Survey: National Survey. 2013. http://www.gov.scot/Resource/0044/ 00440163.pdf (accessed Jan 2016).

21. Unison. Unison Bullying and Harassment Questionnaire. 2013. http:// www.unison-nuh.org.uk/pdf/Survey.pdf (accessed 20 Sep 2014).

22. Parry-Smith W, Morse L, Sutherland A, et al. Bullying and undermining; a threat to both patient care and medical personnel wellbeing? A cross sectional survey of the undergraduates, trainees and consultants in Obstetrics and Gynaecology in the West Midlands. MedEdPublish 2015;6:19. (accessed Oct 2015)

23. Rayner $\mathrm{C}$, Hoel $\mathrm{H}$. A summary review of literature relating to workplace bullying. J Community Appl Soc Psychol 1997;7:181-91.

24. https://www.rcog.org.uk/en/careers-training/workplace-workforceissues/improving-workplace-behaviours-dealing-with undermining/ development/ 